\title{
Pressure Effect on the Deposition in the a-Si:H Films by PECVD Process for Solar Cell Applications
}

\author{
J. Plaza-Castillo $^{1}$, A. García-Barrientos ${ }^{2,3}$, M. Moreno-Moreno ${ }^{4}$, K.Y.Vizcaíno ${ }^{1}$, J.A. Hoyo-Montaño ${ }^{3}$ \\ and G. Valencia-Palomo ${ }^{3}$ \\ 1. Department of Physics, Universidad del Atlántico, Barranquilla, Colombia. \\ 2. Department of Electronics, Autonomous University of Hidalgo State, Hidalgo, México. \\ 3. Department of Electronics, Instituto Tecnológico de Hermosillo, Sonora, México. \\ 4. Department of Electronics, INAOE, Puebla, Mexico.
}

The amorphous silicon (a-Si) is a material which has had a great acceptance in the microelectronic industry field due to its low cost in comparison with the one of crystalline silicon (c-Si). This material has a random network in its atomic structure, since its atoms are not located to either a specific angles or distance. In 1969, Chittik et al. [1] added hydrogen to the amorphous silicon finding a beneficial effect, since it saturated the defects of the network. This finding was key for the development of the amorphous semiconductors. Thus, W. Spear and P. LeComber [2] showed that silicon has semiconducting properties when together with a dopant gas such as phosphine and diborane. The hydrogenated amorphous silicon $(\mathrm{a}-\mathrm{Si}: \mathrm{H})$ appears as a promising material in the photovoltaic industry due to its high absorption coefficient and low manufacturing cost $[3,4]$. Therefore, the optical and electrical properties of a-Si:H films, such as transmittance, absorption coefficient, conductivity, activation energy and thickness are very important. These properties can be optimized by the deposition process parameters, such as power, frequency mode, argon flow rate, temperature and principally the pressure deposition [57]. This parameter has influence in the transmittance, absorption coefficient and conductivity because is proportional to deposition rate and stress (compressive). In this work, the a-Si:H films were fabricated by the Plasma Enhance Chemical Vapor Deposition (PECVD) process at low frequency with a substrate temperature of $300{ }^{\circ} \mathrm{C}$, varying the flow of hydrogen and dopant gases. In this way, implementing the PECVD technique, thin films have been doped with $\mathrm{PH}_{3}$ (n-type) and with $\mathrm{B}_{2} \mathrm{H}_{6}$ (p-type). The procedure was repeated with different values of flow of $\mathrm{PH}_{3}$ and $\mathrm{H}_{2}$ for the $n$-type films and $\mathrm{B}_{2} \mathrm{H}_{6}$ and $\mathrm{H}_{2}$ for $p$ type ones. To investigate the effects of pressure on the deposition in the a-Si:H films, all experimental parameters for various samples were kept constant except for the deposition pressure. The values of RF power, substrate temperature, and deposition time were $10 \mathrm{~W} / \mathrm{cm}^{2}, 300^{\circ} \mathrm{C}$, and 30 minutes, respectively. On the other hand, the deposition pressure was varied to from 725 to 2500 mTorr in order to investigate the effects of this parameter on the films structure. In each experiment, the films were deposited both on glass as well as silicon substrates.

The characterization of samples and the evaluation of the process were done by the measurements of the absorption coefficients, the conductivities, the activation energies and of the thickness of the films. In the Figures 1(a) and (b), we show the AFM images for the $n$-type and $p$-type, respectively, with different deposition pressure values. For both cases, for low deposition pressure values the nanoclusters do not appear, however these appear when the deposition pressure increase, this study reports the analysis of Si nanoparticles of approximately $1.5 \mathrm{~nm}$ in size, see Figure 1(f). A graph of absorption coefficient of aSi:H layer as a function of wavelength is shown in Figure 1(c) and (d), for $n$ and $p$ type, respectively. Note how the absorption coefficient of the a-Si:H drops near its band gap. In this sense, the Figure 1(e) presents the band gap as a function of deposition pressure, we can see the same band gap value, in both type films, for deposition pressure at 2000 mTorr. And due to high absorption coefficient, only $1 \mu \mathrm{m}$ 
thick a-Si:H layer is required to absorb photons of energy higher that the band gap energy. This study suggest to use the deposition pressure from 1500 to 2500 mTorr to obtain a-Si:H films with high performance for solar cell applications.

[1] R. C. Chittick, et al., J. Electrochem. Soc., vol. 116, no. 77, 1969.

[2] W. Spear et al., Solid State Comm., vol.17, no. 9, 1193 pp., 1975.

[3] Jun Ma, et al., Solar Energy Materials and Solar Cells, vol. 123, 228-232 pp., 2014.

[4] K. Ding, et al., Solar Energy Materials and Solar Cells, vol. 95, 3318-3327 pp., 2011.

[5] V. P. Oleshko, et al., Microsc. Microanal., vol. 12, Suppl. S02, 634-635 pp., 2006.

[6] J. Woerdenweber., et al., Solar Energy Materials and Solar Cells, vol. 95, no. 10, 2011.

[7] Jeong C., et al., J. Nanosci. Nanotechnol., vol. 7, No. 11, 4169-73 pp., 2007.

The authors acknowledge funding from the CONACYT-Mexico, grant numbers 169062 and 204419.

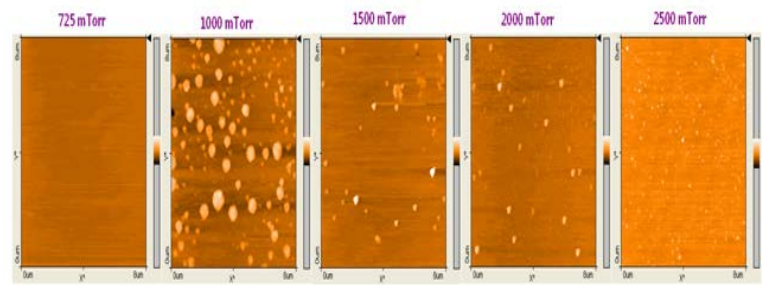

(a)

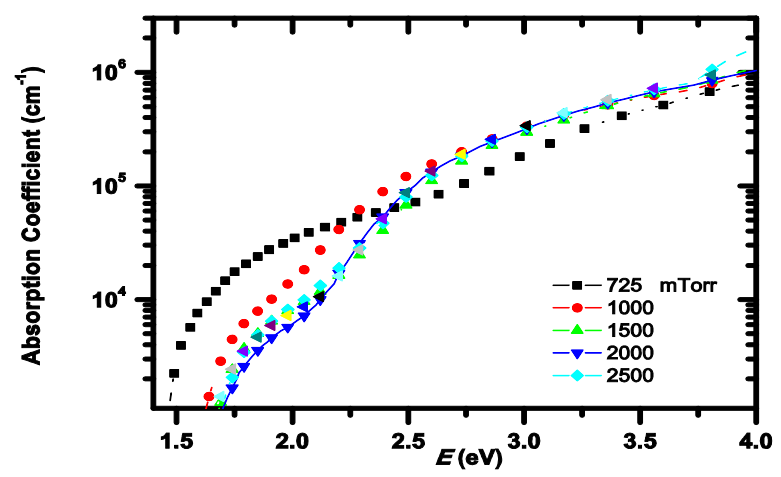

(c)

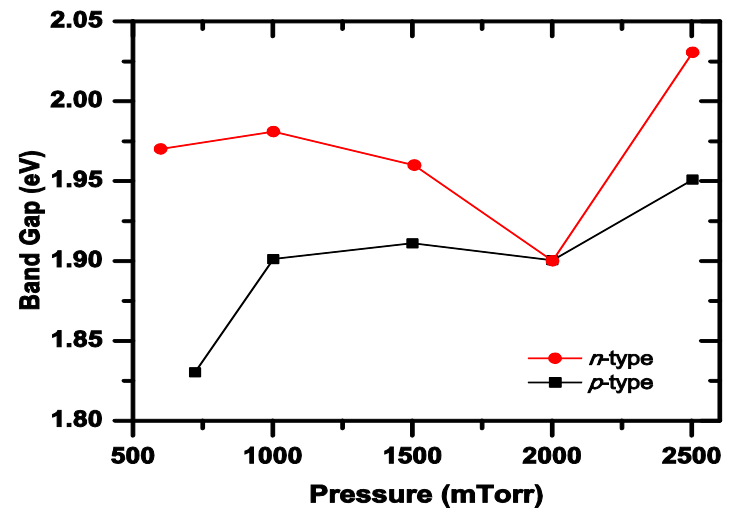

(e)

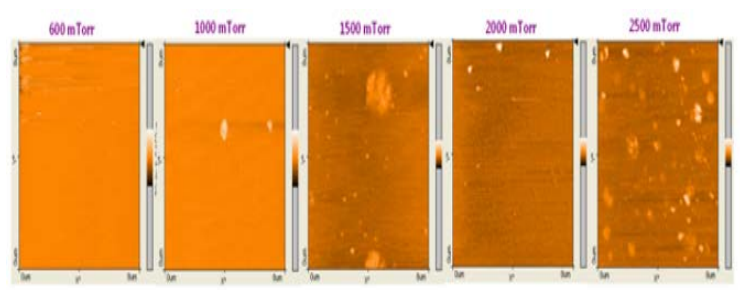

(b)

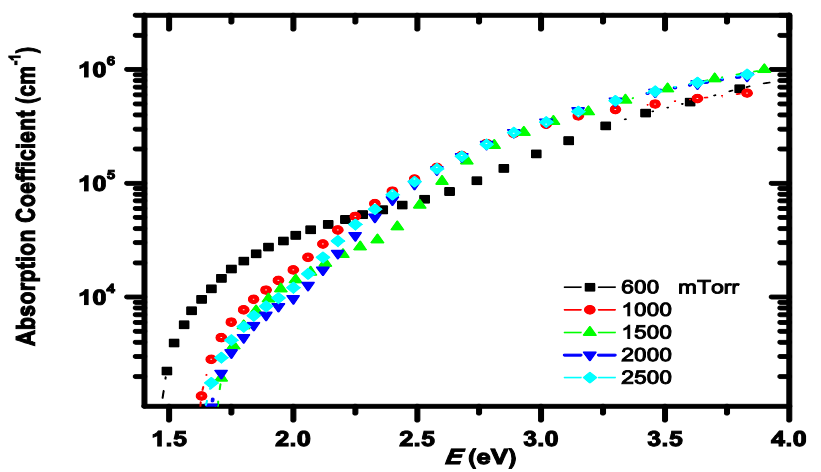

(d)

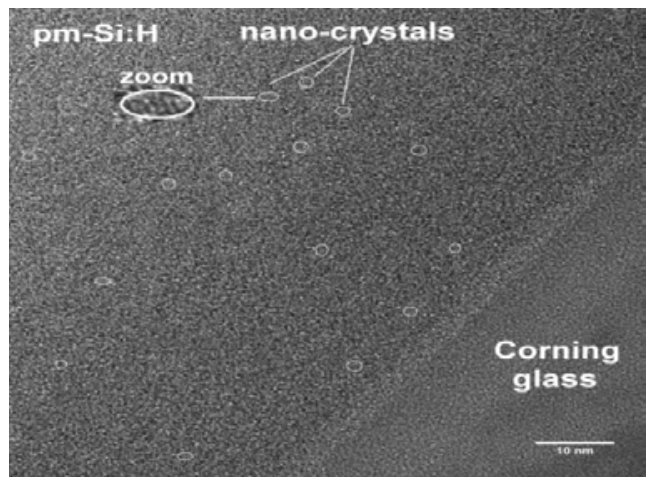

(f)

Figure 1. AFM image for the $n$-type (a) and p-type (b) a-Si:H films. Absorption coefficient of a-Si:H $n$ type (c) and p-type (d) as a function of wavelength. The band gap as a function of deposition pressure for a-Si:H films (e). SEM photo of the sample at 2000 mTorr, where nano-crystals appear (f). 